\title{
The cost-effectiveness of particle therapy in non-small cell lung cancer: Exploring decision uncertainty and areas for future research
}

Citation for published version (APA):

Grutters, J. P. C., Pijls-Johannesma, M., De Ruysscher, D., Peeters, A., Reimoser, S., Severens, J. L., Lambin, P., \& Joore, M. A. (2010). The cost-effectiveness of particle therapy in non-small cell lung cancer: Exploring decision uncertainty and areas for future research. Cancer Treatment Reviews, 36(6), 468-476. https://doi.org/10.1016/j.ctrv.2010.02.018

Document status and date:

Published: 01/10/2010

DOI:

10.1016/j.ctrv.2010.02.018

Document Version:

Publisher's PDF, also known as Version of record

Document license:

Taverne

Please check the document version of this publication:

- A submitted manuscript is the version of the article upon submission and before peer-review. There can be important differences between the submitted version and the official published version of record.

People interested in the research are advised to contact the author for the final version of the publication, or visit the DOI to the publisher's website.

- The final author version and the galley proof are versions of the publication after peer review.

- The final published version features the final layout of the paper including the volume, issue and page numbers.

Link to publication

\footnotetext{
General rights rights.

- You may freely distribute the URL identifying the publication in the public portal. please follow below link for the End User Agreement:

www.umlib.nl/taverne-license

Take down policy

If you believe that this document breaches copyright please contact us at:

repository@maastrichtuniversity.nl

providing details and we will investigate your claim.
}

Copyright and moral rights for the publications made accessible in the public portal are retained by the authors and/or other copyright owners and it is a condition of accessing publications that users recognise and abide by the legal requirements associated with these

- Users may download and print one copy of any publication from the public portal for the purpose of private study or research.

- You may not further distribute the material or use it for any profit-making activity or commercial gain

If the publication is distributed under the terms of Article $25 \mathrm{fa}$ of the Dutch Copyright Act, indicated by the "Taverne" license above, 
ANTI-TUMOUR TREATMENT

\title{
The cost-effectiveness of particle therapy in non-small cell lung cancer: Exploring decision uncertainty and areas for future research
}

\author{
Janneke P.C. Grutters ${ }^{\mathrm{a}, \mathrm{b}, *}$, Madelon Pijls-Johannesma ${ }^{\mathrm{a}, \mathrm{f}}$, Dirk De Ruysscher ${ }^{\mathrm{a}, \mathrm{f}}$, Andrea Peeters ${ }^{\mathrm{a}, \mathrm{f}}$, \\ Stefan Reimoser ${ }^{c, g}$, Johan L. Severens ${ }^{b, d, h}$, Philippe Lambin ${ }^{\mathrm{a}, \mathrm{e}, \mathrm{f}}$, Manuela A. Joore ${ }^{\mathrm{b}, \mathrm{d}, \mathrm{e}, \mathrm{i}}$

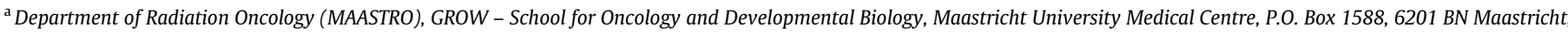 \\ The Netherlands \\ ${ }^{\mathrm{b}}$ Department of Health Organization, Policy and Economics, Maastricht University, P.O. Box 616, 6200 MD Maastricht, The Netherlands \\ ${ }^{\mathrm{c}}$ Turner and Townsend GmbH, St.-Martin-Straße 76, 81541 München, Germany \\ ${ }^{\mathrm{d}}$ Department of Clinical Epidemiology and Medical Technology Assessment, Maastricht University Medical Centre, P.O. Box 5800, 6202 AZ Maastricht, The Netherlands
}

\section{A R T I C L E I N F O}

\section{Article history:}

Received 11 January 2010

Received in revised form 17 February 2010

Accepted 23 February 2010

\section{Keywords:}

Economic evaluation

Particle therapy

Protons

Carbon-ions

Lung cancer

Evidence synthesis

\begin{abstract}
S U M M A R Y
Purpose: To review and synthesize all available evidence in order to explore the cost-effectiveness of particle therapy (carbon-ions, protons) compared to the best current treatments for non-small-cell lung cancer (NSCLC), and the value of additional research. The present study focuses on stage I NSCLC, as no data is available for more advanced stages.

Methods: A probabilistic decision-analytic Markov model was constructed to synthesize all available evidence. Comparative treatments were carbon-ions, protons, conventional radiotherapy (CRT) and stereotactic radiotherapy (SBRT) for inoperable stage I NSCLC; and carbon-ions and SBRT for operable stage I NSCLC. The expected value of perfect information (EVPI) was calculated to support research decisions. Results: For inoperable stage I NSCLC, carbon-ion therapy costed $€ 67.257$ per quality-adjusted-life-year gained compared to SBRT. Both treatments dominated protons and CRT. Considerable uncertainty surrounded these results, resulting in a high EVPI. For operable stage I NSCLC SBRT dominated carbon-ion therapy.

Conclusions: Due to the considerable uncertainty in stage I NSCLC, and the lack of data on more advanced stages, it is recommended not to adopt particle therapy as standard treatment in NSCLC yet. More evidence is needed to reduce the decision uncertainty and to support evidence-based treatment decisions. It might be worthwhile to invest in a particle facility for clinical research. Future research should also weigh the investment risk, value of information and costs of delay.
\end{abstract}

(c) 2010 Elsevier Ltd. All rights reserved.

\section{Introduction}

Lung cancer is estimated to be the leading cause of cancer death in 2009. ${ }^{1}$ Despite improvements in diagnostics and treatment, the

\footnotetext{
* Corresponding author. Address: Department of Health Organization, Policy and Economics, Maastricht University, P.O. Box 616, 6200 MD Maastricht, The Netherlands. Tel.: +31 433881973; fax: +31 433670960.

E-mail addresses: janneke.grutters@maastro.nl (J.P.C. Grutters), madelon.pijls@maastro.nl (M. Pijls-Johannesma), dirk.deruysscher@maastro.nl (D.D. Ruysscher), andrea.peeters@maastro.nl (A. Peeters), stefan.reimoser@turntown.com (S. Reimoser), h.severens@beoz.unimaas.nl (J.L. Severens), philippe.lambin@maastro.nl (P. Lambin), m.joore@mumc.nl (M.A. Joore).

e These authors contributed equally to this work.

f Tel.: +31 884455666; fax: +31 884455667 .

g Tel.: +4989636 86928; fax: +498963681973.

h Tel.: +31 433882907; fax: +31 433670960 .

i Tel.: +31 43 3875434; fax: +31433874419.
}

prognosis of lung cancer patients remains poor, with 5-year overall survival rates between $6 \%$ and $18 \%{ }^{2}$ As local tumor failure remains high, new ways to deliver radiotherapy beyond photons have been examined, including protons and carbon-ions. Because of their superior dose-distribution and for carbon-ions also their biological characteristics, a clinical benefit is expected with these charged particles. Particle therapy could minimize the extent and severity of normal tissue injury, and/or permit an increased dose to the tumor, thereby improving local tumor control. However, particle therapy is associated with considerable investment costs, and there already is increasing concern about the substantial increase in the cost of cancer care worldwide. ${ }^{3}$ Currently, decisions need to be made worldwide whether or not to adopt particle therapy as standard treatment, and for which indications, and whether or not to invest in particle facilities. Since resources are scarce, we need to examine whether the effects of new technologies such as particle therapy are worth the extra $\operatorname{costs}^{4}$, to allow for 
evidence-based decision-making. Economic evaluation is a method to examine this trade-off between costs and effects of comparative treatments. However, economic evaluation on particle therapy requires effectiveness data, which for lung cancer are only available in stage I non-small cell lung cancer (NSCLC). ${ }^{5}$ The present study therefore focuses on stage I NSCLC.

Since the clinical effect has not yet been investigated in comparative studies ${ }^{6}$, economic evaluation on particle therapy in NSCLC will need to draw on evidence from a range of sources. Decisionanalytic modeling is a tool to synthesize available evidence from different sources to inform decision-making under conditions of uncertainty. ${ }^{7,8}$ Additionally, one can assess the value of additional research, and specifically what type of evidence would be most valuable. It can therefore assist in making a twofold decision: (1) whether an intervention should be adopted, given the current evidence, and (2) whether it is worthwhile to perform additional research to reduce uncertainty surrounding the first decision. ${ }^{9}$ This second decision is especially relevant in the light of the ongoing debate regarding randomized trials in particle therapy. ${ }^{10-19}$

The current paper aims to review and synthesize all available evidence in a decision-analytic Markov model, to (1) explore the cost-effectiveness of particle therapy, both protons and carbonions, compared to the best currently available treatments for stage I NSCLC, and (2) to assess the value of additional research, and for which topics further research is most valuable.

\section{Methods}

\section{Model description}

A decision-analytic Markov model was constructed with mutually exclusive health states, to compare the expected costs and effects of comparative treatment modalities. In this model each cycle a hypothetical cohort of NSCLC patients moves between the health states according to a set of transition probabilities. The cycle length of the model was one year. A five-year time horizon was used, because the proportion of events occurring after five years is small and no data were available beyond this time point. Comparative treatments depended on whether patients were medically operable. First, for inoperable stage I NSCLC, carbon-ion and proton therapy were compared to conventional radiotherapy (CRT) and stereotactic body radiotherapy (SBRT). Second, for operable stage I NSCLC, carbon-ion and proton therapy were compared to SBRT. When carbon-ion and/or proton therapy were cost-effective compared to SBRT, surgery would also be included as a comparator. The Markov model was built and analyzed in Microsoft Office Excel 2003.

\section{Model construction}

\section{Health states}

Health states were based on whether patients were alive and whether they had grade 3 or higher irreversible dyspnoea (Fig. 1). Intermediate states were used to represent acute adverse events (pneumonitis or oesophagitis grade 3 or more or treatment-related death) in the first six weeks during or directly after radiotherapy. Adverse events were graded according to the $\mathrm{Na}-$ tional Cancer Institute Common Terminology Criteria for Adverse Events (CTCAE) ${ }^{20}$ The final absorbing state was 'death', either due to cancer or due to other causes. Radiation-induced secondary malignancies were not incorporated in the model. Although one of the proposed advantages of particle therapy is that its reduced integral dose may reduce the development of radiation-induced secondary cancers, it is difficult to quantify the risk of secondary cancers, and to date there is no consensus on how this should be

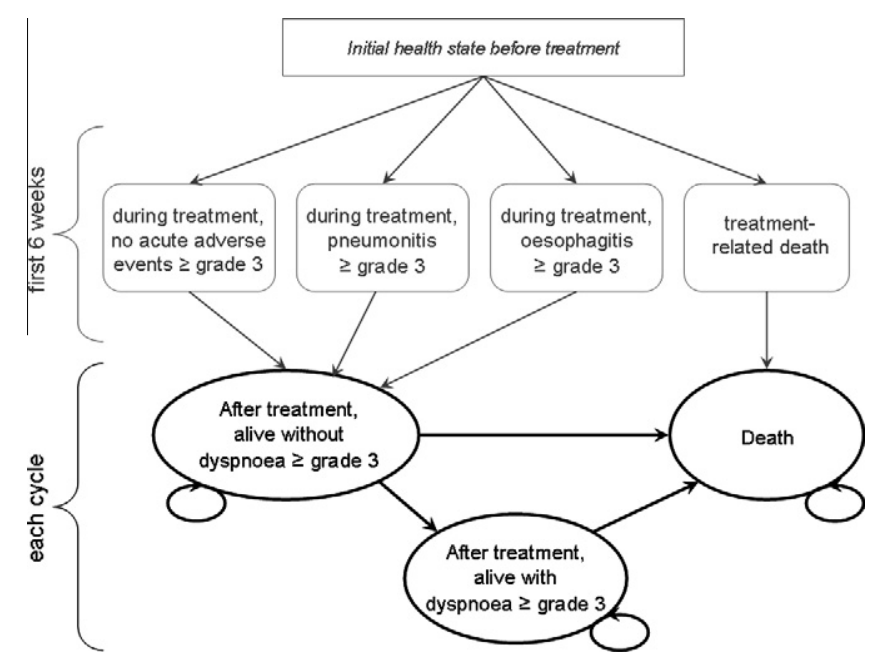

Fig. 1. Schematic diagram of the Markov model.

measured. $^{21-23}$ Also, the relevance of this advantage in the NSCLC population of patients with relatively old age and poor prognosis is doubtful.

\section{Probabilities}

Transition probabilities were derived for each cycle from a systematic literature review and meta-analysis ${ }^{5}$, and are listed in Table $1 \mathrm{a}$.

First, for inoperable stage I NSCLC, we included published studies that reported survival data on CRT, SBRT, proton therapy and carbon-ion therapy. ${ }^{5}$ The 2- and 5-year overall and disease-specific survival as well as the occurrence of adverse events was extracted from the publications.

Second, for operable stage I NSCLC we extracted data for SBRT from two studies reporting on 128 operable patients separately. ${ }^{24,25}$ Data on 31 operable patients in the most recent carbon-ion studies were derived through personal communication with the author. ${ }^{26,27}$ Because of data constraints proton therapy was excluded as a comparator, and all deaths were assumed to be due to other causes. The occurrence of adverse events was assumed to be similar to the inoperable group.

Data from the separate studies were pooled using a random effects meta-regression, using STATA 9 software. ${ }^{5}$ For inoperable stage I disease, pooled results were corrected for differences between study populations regarding the percentage of medically inoperable patients. The 2-year and 3-5-year survival rates were converted to yearly probabilities. ${ }^{8}$

\section{Effects}

Health-related quality of life was used as outcome measure in the model. It was considered as single index utility, on a scale from 0 (representing death) to 1 (representing perfect health). ${ }^{4}$ The use of utility scores allows the calculation of Quality Adjusted Life Years (QALYs) and cost per QALY ratios. Utility scores were derived from NSCLC patients treated with curative intent in the past five years, in a cross-sectional survey. Patients were treated with radiotherapy, surgery, chemotherapy or a combination of these modalities. Eligible patients who were treated in the south (Maastricht University Medical Centre region) or north (University Medical Centre Groningen region) of the Netherlands were selected from the national cancer registry. Respondents completed the EuroQol-5D ${ }^{28}$ and questions regarding adverse events, based on the CTCAE. $^{20}$ The answers on the Euroqol-5D were transformed into a utility score using a scoring function. ${ }^{29}$ Mean utility scores and 
Table 1a

List of input parameters for the transition probabilities.

\begin{tabular}{|c|c|c|c|c|c|c|c|c|}
\hline & \multicolumn{4}{|l|}{ Base case analysis } & \multicolumn{4}{|c|}{ Analysis with studies from 2005} \\
\hline & Estimated value & SE & Distribution & Source & Estimated value & SE & Distribution & Source \\
\hline \multicolumn{9}{|c|}{ Inoperable stage I NSCLC } \\
\hline \multicolumn{9}{|c|}{ For conventional radiotherapy with photons (CRT) } \\
\hline Treatment-related death & 0.001 & 0.001 & Beta & [5] & 0.001 & 0.001 & Beta & {$[5]$} \\
\hline Acute pneumonitis $\geqslant$ grade 3 & 0.002 & 0.004 & Beta & [5] & 0.002 & 0.004 & Beta & [5] \\
\hline Acute oesophagitis $\geqslant$ grade 3 & 0.001 & 0.004 & Beta & [5] & 0.001 & 0.004 & Beta & [5] \\
\hline Irreversible dyspnoea $\geqslant$ grade 3 & 0.005 & 0.002 & Beta & [5] & 0.005 & 0.002 & Beta & [5] \\
\hline Disease mortality year $1-2$ & 0.179 & 0.027 & Dirichlet & [5] & 0 & Fixed & & $\ddagger$ \\
\hline Other mortality year $1-2$ & 0.092 & 0.027 & Dirichlet & [5] & 0.261 & 0.073 & Beta & [5] \\
\hline Disease mortality year $3-5$ & 0.135 & 0.027 & Dirichlet & [5] & 0 & Fixed & & $\ddagger$ \\
\hline Other mortality year 3-5 & 0.151 & 0.027 & Dirichlet & [5] & 0.258 & 0.056 & Beta & {$[5]$} \\
\hline \multicolumn{9}{|c|}{ For stereotactic body radiotherapy with photons (SBRT) } \\
\hline Treatment-related death & 0.007 & 0.003 & Beta & [5] & 0.007 & 0.003 & Beta & {$[5]$} \\
\hline Acute pneumonitis $\geqslant$ grade 3 & 0.020 & 0.005 & Beta & [5] & 0.021 & 0.005 & Beta & [5] \\
\hline Acute oesophagitis $\geqslant$ grade 3 & 0.002 & 0.002 & Beta & [5] & 0.003 & 0.002 & Beta & [5] \\
\hline Irreversible dyspnoea $\geqslant$ grade 3 & 0.008 & 0.003 & Beta & [5] & 0.008 & 0.003 & Beta & [5] \\
\hline Disease mortality year $1-2$ & 0.087 & 0.023 & Dirichlet & [5] & 0 & Fixed & & \pm \\
\hline Other mortality year $1-2$ & 0.076 & 0.023 & Dirichlet & [5] & 0.165 & 0.027 & Beta & [5] \\
\hline Disease mortality year 3-5 & 0.105 & 0.028 & Dirichlet & [5] & 0 & Fixed & & $\ddagger$ \\
\hline Other mortality year 3-5 & 0.063 & 0.028 & Dirichlet & [5] & 0.164 & 0.030 & Beta & [5] \\
\hline \multicolumn{9}{|l|}{ For proton therapy } \\
\hline Treatment-related death & 0.004 & 0.006 & Beta & [5] & 0.008 & 0.012 & Beta & {$[5]$} \\
\hline Acute pneumonitis $\geqslant$ grade 3 & 0.008 & 0.008 & Beta & [5] & 0.017 & 0.017 & Beta & [5] \\
\hline Acute oesophagitis $\geqslant$ grade 3 & 0.004 & 0.006 & Beta & [5] & 0.008 & 0.012 & Beta & [5] \\
\hline Irreversible dyspnoea $\geqslant$ grade 3 & 0.008 & 0.012 & Beta & [5] & 0.008 & 0.012 & Beta & [5] \\
\hline Disease mortality year $1-2$ & 0.139 & 0.040 & Dirichlet & [5] & 0 & Fixed & & $\ddagger$ \\
\hline Other mortality year 1-2 & 0.078 & 0.040 & Dirichlet & [5] & 0.135 & 0.071 & Beta & [5] \\
\hline Disease mortality year 3-5 & 0.103 & 0.041 & Dirichlet & [5] & 0 & Fixed & & 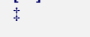 \\
\hline Other mortality year 3-5 & 0.078 & 0.041 & Dirichlet & [5] & 0.128 & 0.067 & Beta & {$[5]$} \\
\hline \multicolumn{9}{|l|}{ For carbon-ion therapy } \\
\hline Treatment-related death & 0.002 & 0.003 & Beta & [5] & 0.004 & 0.005 & Beta & [5] \\
\hline Acute pneumonitis $\geqslant$ grade 3 & 0.014 & 0.008 & Beta & [5] & 0.004 & 0.005 & Beta & [5] \\
\hline Acute oesophagitis $\geqslant$ grade 3 & 0.002 & 0.003 & Beta & {$[5]^{*}$} & 0.004 & 0.005 & Beta & [5] \\
\hline Irreversible dyspnoea $\geqslant$ grade 3 & 0.002 & 0.003 & Beta & [5] & 0.004 & 0.005 & Beta & [5] \\
\hline Disease mortality year $1-2$ & 0.097 & 0.033 & Dirichlet & [5] & 0 & Fixed & & $\ddagger$ \\
\hline Other mortality year 1-2 & 0.044 & 0.033 & Dirichlet & [5] & 0.138 & 0.053 & Beta & [5] \\
\hline Disease mortality year 3-5 & 0.078 & 0.030 & Dirichlet & [5] & 0 & Fixed & & $\ddagger$ \\
\hline Other mortality year 3-5 & 0.097 & 0.030 & Dirichlet & [5] & 0.156 & 0.044 & Beta & [5] \\
\hline \multicolumn{9}{|c|}{ Operable stage I NSCLC } \\
\hline \multicolumn{9}{|c|}{ For stereotactic body radiotherapy with photons (SBRT) } \\
\hline Treatment-related death & 0.007 & 0.003 & Beta & [5] & & & & \\
\hline Acute pneumonitis $\geqslant$ grade 3 & 0.020 & 0.005 & Beta & [5] & & & & \\
\hline Acute oesophagitis $\geqslant$ grade 3 & 0.002 & 0.002 & Beta & [5] & & & & \\
\hline Irreversible dyspnoea $\geqslant$ grade 3 & 0.008 & 0.003 & Beta & [5] & & & & \\
\hline Mortality year $1-2$ & 0.068 & 0.016 & Beta & {$[24,25]$} & & & & \\
\hline Mortality year 3-5 & 0.094 & 0.018 & Beta & {$[24,25]$} & & & & \\
\hline \multicolumn{9}{|l|}{ For carbon-ion therapy } \\
\hline Treatment-related death & 0.002 & 0.003 & Beta & [5] & & & & \\
\hline Acute pneumonitis $\geqslant$ grade 3 & 0.014 & 0.008 & Beta & [5] & & & & \\
\hline Acute oesophagitis $\geqslant$ grade 3 & 0.002 & 0.003 & Beta & [5] & & & & \\
\hline Irreversible dyspnoea $\geqslant$ grade 3 & 0.002 & 0.003 & Beta & [5] & & & & \\
\hline Mortality year $1-2$ & 0.067 & 0.032 & Beta & PC, $[26,27]$ & & & & \\
\hline Mortality year 3-5 & 0.114 & 0.035 & Beta & PC, $[26,27]$ & & & & \\
\hline
\end{tabular}

SE, standard error; PC, personal communication; EO, expert opinion.

\$ Due to a lack of data on disease-specific survival we assumed all deaths to be due to other causes.

* Since none of the carbon-ion studies reported $\geqslant$ grade 3 oesophagitis, it was assumed that no events occurred.

standard errors were calculated for respondents with $(n=43)$ and without ( $n=203$ ) dyspnoea grade 3 or higher (Table $1 \mathrm{~b}$ ). Since no data were available on utility scores for acute adverse events we assumed the utility score for late adverse events to also apply there. Future effects were discounted to their present value by a rate of $1.5 \%$, according to the Dutch guidelines. ${ }^{30}$

\section{Costs}

A health-care perspective was used. All costs were reported in Euros and are listed in Table 1c. Price indices were used to convert costs to the 2007 price level. Where possible, unit costs were based on the Dutch manual for cost research. ${ }^{31}$ For radiation therapy (photons, protons and carbon-ions) a detailed cost analysis was performed. ${ }^{32}$ In this cost analysis a mature particle facility with use of its maximum capacity was assumed. Because the optimal number of fractions is not yet known for particle therapy, we used the number of fractions that was reported in the published studies. Future costs were discounted to their present value by a rate of $4 \%{ }^{30}$

\section{Analysis}

\section{Base case analysis}

For both patient groups (inoperable stage I, operable stage I) a model was built. Incremental cost-effectiveness ratios (ICERs) were 
Table 1b

List of input parameters for the effects.

\begin{tabular}{lllll}
\hline & $\begin{array}{l}\text { Estimated } \\
\text { value }\end{array}$ & SE & Distribution & Source \\
\hline $\begin{array}{c}\text { After treatment, no adverse } \\
\text { events }\end{array}$ & 0.81 & 0.013 & Beta & CSS \\
$\begin{array}{c}\text { After treatment, irreversible } \\
\text { dyspnoea } \geqslant \text { grade 3 } \\
\begin{array}{c}\text { During treatment, no adverse } \\
\text { events }\end{array}\end{array}$ & 0.46 & 0.050 & Beta & CSS \\
$\begin{array}{c}\text { During treatment, acute } \\
\text { pneumonitis } \geqslant \text { grade 3 }\end{array}$ & 0.46 & 0.050 & Beta & CSS $^{\dagger}$ \\
$\begin{array}{c}\text { During treatment, acute } \\
\text { oesophagitis } \geqslant \text { grade 3 }\end{array}$ & 0.46 & 0.050 & Beta & CSS $^{\dagger}$ \\
\hline
\end{tabular}

SE, standard error; CSS, cross-sectional survey.

${ }^{\dagger}$ Because no data were available on the utility scores during treatment, we estimated these to be equal to the utility scores after treatment, with or without adverse events.

calculated from each model, by dividing the incremental costs by the incremental QALYs. Whether a treatment is deemed cost-effec- tive depends on how much society is willing to pay for a gain in effect, which is referred to as the ceiling ratio. In the Netherlands an informal ceiling ratio of $€ 80.000$ per QALY exists for diseases with a high burden of disease. ${ }^{33}$

The current analysis was performed from a decision-analytic perspective, which implies that for a treatment to be adopted it should have the highest net monetary benefit (NMB), instead of being statistically significantly more cost-effective than its comparator. ${ }^{9}$ The NMB assigns a monetary value to the benefit achieved, and subtracts from this the cost of achieving this benefit.

Uncertainty surrounding the ICERs was handled probabilistically. This means that we assigned distributions to the model parameters, to reflect the uncertainty in the estimation of that parameter. ${ }^{8}$ Parameter values were drawn at random from the assigned distributions, using Monte Carlo simulation with 10.000 iterations. To illustrate the results of the simulation, cost-effectiveness acceptability curves (CEACs) were calculated. ${ }^{34}$ CEACs show the probability that a treatment has the highest $\mathrm{NMB}$, and thus is cost-effective, given different ceiling ratios. They simultaneously show the probability that the 'wrong' decision will be made by

Table 1c

List of input parameters for the costs.

\begin{tabular}{|c|c|c|c|c|}
\hline & Estimated value & SE & Distribution & Source \\
\hline Probability of hospital admission due to acute pneumonitis $\geqslant$ grade 3 & 0.025 & 0.003 & Beta & EO \\
\hline Probability of hospital admission due to acute oesophagitis $\geqslant$ grade 3 & 1 & Fixed & & EO \\
\hline Yearly costs of having irreversible dyspnoea $\geqslant$ grade $3(€)$ & 1045 & 100 & Gamma & + \\
\hline \multicolumn{5}{|l|}{ Resource use } \\
\hline Number of minutes per fraction & 10 & $8-18^{*}$ & Beta PERT & EO \\
\hline Number of fractions & 35 & $20-44^{*}$ & Beta PERT & {$[5]$} \\
\hline $\begin{array}{l}\text { Related to SBRT } \\
\text { Number of minutes per fraction } \\
\text { Number of fractions }\end{array}$ & $\begin{array}{l}35 \\
4\end{array}$ & $\begin{array}{l}30-40^{*} \\
1-14^{*}\end{array}$ & $\begin{array}{l}\text { Beta PERT } \\
\text { Beta PERT }\end{array}$ & $\begin{array}{l}\text { EO } \\
{[5]}\end{array}$ \\
\hline $\begin{array}{l}\text { Related to proton therapy } \\
\text { Number of minutes per fraction } \\
\text { Number of fractions }\end{array}$ & $\begin{array}{l}25 \\
15\end{array}$ & $\begin{array}{l}20-30^{*} \\
10-20^{*}\end{array}$ & $\begin{array}{l}\text { Beta PERT } \\
\text { Beta PERT }\end{array}$ & $\begin{array}{l}\text { EO } \\
{[5]}\end{array}$ \\
\hline $\begin{array}{l}\text { Related to carbon-ion therapy } \\
\text { Number of minutes per fraction } \\
\text { Number of fractions }\end{array}$ & $\begin{array}{l}35 \\
4\end{array}$ & $\begin{array}{l}30-40^{*} \\
1-18^{*}\end{array}$ & $\begin{array}{l}\text { Beta PERT } \\
\text { Beta PERT }\end{array}$ & $\begin{array}{l}\text { EO } \\
{[5]}\end{array}$ \\
\hline $\begin{array}{l}\text { Related to adverse events } \\
\text { Days of hospital admission with acute pneumonitis } \geqslant \text { grade } 3 \\
\text { Days of hospital admission with acute oesophagitis } \geqslant \text { grade } 3 \\
\text { Days of tube feeding with oesophagitis } \\
\text { Months of medication for pneumonitis } \\
\text { Months of medication for oesophagitis }\end{array}$ & $\begin{array}{l}11 \\
2 \\
21 \\
1.5 \\
1\end{array}$ & $\begin{array}{l}2 \\
0.3 \\
2 \\
\text { Fixed } \\
\text { Fixed }\end{array}$ & $\begin{array}{l}\text { Gamma } \\
\text { Gamma } \\
\text { Gamma }\end{array}$ & $\begin{array}{l}+ \\
\text { EO } \\
\text { EO } \\
\text { EO } \\
\text { EO }\end{array}$ \\
\hline $\begin{array}{l}\text { Related to follow-up after treatment } \\
\text { Number of follow-up visits in first year } \\
\text { Number of follow-up visits in second year } \\
\text { Number of follow-up visits after second year }\end{array}$ & $\begin{array}{l}4 \\
2 \\
1\end{array}$ & $\begin{array}{l}\text { Fixed } \\
\text { Fixed } \\
\text { Fixed }\end{array}$ & & $\begin{array}{l}\ddagger \\
\vdots \\
\vdots\end{array}$ \\
\hline \multicolumn{5}{|l|}{ Unit costs $(€)$} \\
\hline Fraction of photons (10 min) & 233 & $194-291^{*}$ & Beta PERT & [32] \\
\hline Fraction of protons (10 min) & 413 & $344-516^{*}$ & Beta PERT & {$[32]$} \\
\hline Fraction of carbon-ions (10 min) & 627 & $522-783^{*}$ & Beta PERT & {$[32]$} \\
\hline Hospital admission per day & 356 & Fixed & & [31] \\
\hline Medication costs for pneumonitis per month (70 kg) & 19 & Fixed & & \# \\
\hline Medication costs for oesophagitis per month & 30 & Fixed & & \# \\
\hline Placing/removing tube when hospitalized for acute oesophagitis & 100 & Fixed & & [31] \\
\hline Tube nutrition per day & 18 & Fixed & & MP \\
\hline Follow-up visit & 59 & Fixed & & [31] \\
\hline Death due to cancer & 21675 & 2000 & Gamma & $\S$ \\
\hline Death due to other causes & 15449 & 2000 & Gamma & $\S$ \\
\hline
\end{tabular}

SE, standard error; EO, expert opinion; MP, market price.

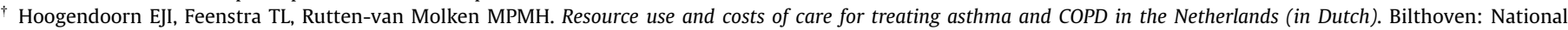
Institute for Public Health and the Environment; 2004.

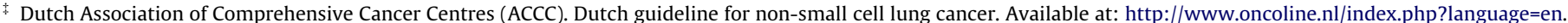
2004.

\# Health Care Insurance Board. Pharmacotherapeutic compass. Diemen: Health Care Insurance Board; 2007.

$\S$ Kommer GJ, Slobbe LCJ, Polder JJ. Risk solidarity and health-care costs. Bilthoven: National Institute for Public Health and the Environment; 2005.

Minimum and maximum value is listed instead of standard error for beta PERT distributions. 
Table 2

Results of the cost-effectiveness analyses.

\begin{tabular}{|c|c|c|c|c|}
\hline & Expected costs in $€\left(95 \% \mathrm{Cl}^{*}\right)$ & Expected QALYs $\left(95 \% \mathrm{CI}^{*}\right)$ & & ICER ( $€$ per QALY) \\
\hline \multicolumn{5}{|c|}{ Inoperable stage I NSCLC } \\
\hline Carbon-ions & $19.215(14.273-27.415)$ & $2.67(2.28-3.04)$ & & \\
\hline & & & \} & 67.257 \\
\hline SBRT & $13.871(11.124-17.413)$ & $2.59(2.31-2.88)$ & & \\
\hline Protons & $27.567(22.713-32.638)$ & $2.33(1.96-2.74)$ & & Dominated by carbon-ions and SBRT \\
\hline CRT & $22.696(19.566-26.274)$ & $1.98(1.78-2.20)$ & & Dominated by carbon-ions and SBRT \\
\hline \multicolumn{5}{|c|}{ Operable stage I NSCLC ${ }^{* *}$} \\
\hline SBRT & $8.485(6.497-11.613)$ & $3.20(3.03-3.36)$ & & \\
\hline Carbon-ions & $14.620(10.231-22.694)$ & $3.16(2.86-3.42)$ & & Dominated by SBRT \\
\hline \multicolumn{5}{|c|}{ Sensitivity analysis: inoperable stage I NSCLC using studies from 2005} \\
\hline Protons & $22.815(18.124-28.219)$ & $2.79(2.25-3.26)$ & & \\
\hline \multirow{3}{*}{ Carbon-ions } & & & \} & 81.479 \\
\hline & $16.875(12.293-25.314)$ & $2.72(2.33-3.07)$ & & \\
\hline & & & \} & 36.017 \\
\hline SBRT & $11.878(9.308-15.603)$ & $2.58(2.37-2.78)$ & & \\
\hline CRT & $19.561(15.961-23.785)$ & $2.05(1.66-2.44)$ & & Dominated by carbon-ions and SBRT \\
\hline
\end{tabular}

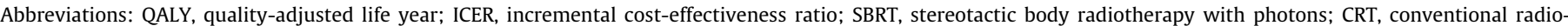
therapy with photons.

* CI, confidence interval. Confidence intervals are based on probabilistic sensitivity analysis.

** Surgery not included as a comparator because SBRT dominated carbon-ion therapy.

implementing the treatment that, based on the currently available evidence, appears to be the most cost-effective.

\section{Sensitivity analysis}

In addition to the probabilistic sensitivity analysis, a separate sensitivity analysis was performed. In this sensitivity analysis we calculated the probabilities for inoperable stage I NSCLC using only studies that were published after 2004. We did this because all but one SBRT studies were published after 2004, while especially CRT studies were overall older. This may influence the results, because oncology care and disease staging for NSCLC have improved in the last decade. ${ }^{35}$ Because the newer studies on CRT did not report on adverse events we based these probabilities on all studies. Also, due to limited data on disease-specific survival we used only overall survival rates.

\section{Value of information analysis}

As uncertainty exists, there is always a chance that the 'wrong' decision will be made. ${ }^{8}$ The expected value of perfect information (EVPI) is a measure of the worth of acquiring additional information, through further research. ${ }^{36}$ The EVPI is the expected value of obtaining perfect knowledge of the 'true' values of all parameters. We calculated the EVPI by subtracting the NMB of the treatment we would choose under uncertainty, from the NMB of the decision we would make if we knew the 'true' parameter values. The population EVPI is calculated by multiplying the EVPI per patient by the number of patients that could potentially benefit from additional research. ${ }^{36}$ Population EVPI values were calculated for the Netherlands, using an estimated annual incidence of 337 (incidence rate for the year 2007) ${ }^{37}$, assuming a 10-year lifespan of the technology and a discount rate of $4 \%{ }^{30}$ Finally, we calculated the EVPI for parameter groups, for a ceiling ratio of $€ 80.000$, to examine on which topics further research is most valuable.

\section{Results}

\section{Base case analysis}

For inoperable stage I NSCLC carbon-ion therapy yielded the most QALYs per patient (2.67), for a total expected health-care cost of $€ 19.215$ per patient over 5 years (Table 2). SBRT yielded less QALYs (2.59), but was also less expensive ( $€ 13.781)$. This resulted in an ICER of $€ 67.257$ per QALY gained for carbon-ions compared to SBRT. Proton therapy (2.33 QALYs) and CRT (1.98 QALYs) were both less effective and more expensive, and thus dominated by both carbon-ion therapy and SBRT. For a ceiling ratio of $€ 80.000$ carbon-ion therapy had the highest probability of being cost-effective (52\%), followed by SBRT (47\%), proton therapy (2\%) and CRT $(0 \%)$. The CEACs are presented in Fig. 2a.

For operable stage I NSCLC SBRT yielded 3.20 QALYs, while carbon-ion therapy yielded 3.16 QALYs (Table 2). The expected total health-care costs per patient were $€ 8.485$ and $€ 14.620$, respectively. SBRT was thus on average more effective and less expensive than carbon-ion therapy. For a ceiling ratio of $€ 80.000$ SBRT had a $78 \%$ probability of being cost-effective, versus $22 \%$ for carbon-ion therapy (Fig. 2b). Because carbon-ion therapy was not cost-effective compared to SBRT, surgery was not included as a comparator.

\section{Sensitivity analysis}

In a sensitivity analysis we pooled only studies on effectiveness that were published after 2004. Proton therapy was found to be the most effective (2.79 QALYs) and most expensive ( $€ 22.815)$. Carbonion therapy was less effective (2.72 QALYs) and less expensive ( $€ 16.875)$ than protons, resulting in an ICER of $€ 81.479$ per QALY gained (Table 2). Given a ceiling ratio of $€ 80.000$ per QALY, protons are not cost-effective compared to carbon-ions. Carbon-ion therapy was more effective and more expensive than SBRT, resulting in an acceptable ICER of $€ 36.017$ per QALY gained. CRT was dominated by carbon-ion therapy. For a ceiling ratio of $€ 80.000$ proton therapy had a $46 \%$ probability of being cost-effective (Fig. $2 \mathrm{c}$ ), followed by carbon-ion therapy (38\%), SBRT (16\%) and CRT (0\%).

\section{Value of information}

For the base case analysis of inoperable stage I NSCLC, the uncertainty surrounding the decision whether to adopt particle therapy resulted in an EVPI of $€ 7.784$ per patient, given a ceiling ratio of $€ 80.000$. Adopting particle therapy will affect all patients with inoperable stage I NSCLC in the Netherlands, being a total of 2.843 patients in the next 10 years. This makes the population EVPI $€ 22$ million, meaning that the upper bound of the value of additional research for the Netherlands is $€ 22$ million. The population EVPI for different ceiling ratios is presented in Fig. 3. 

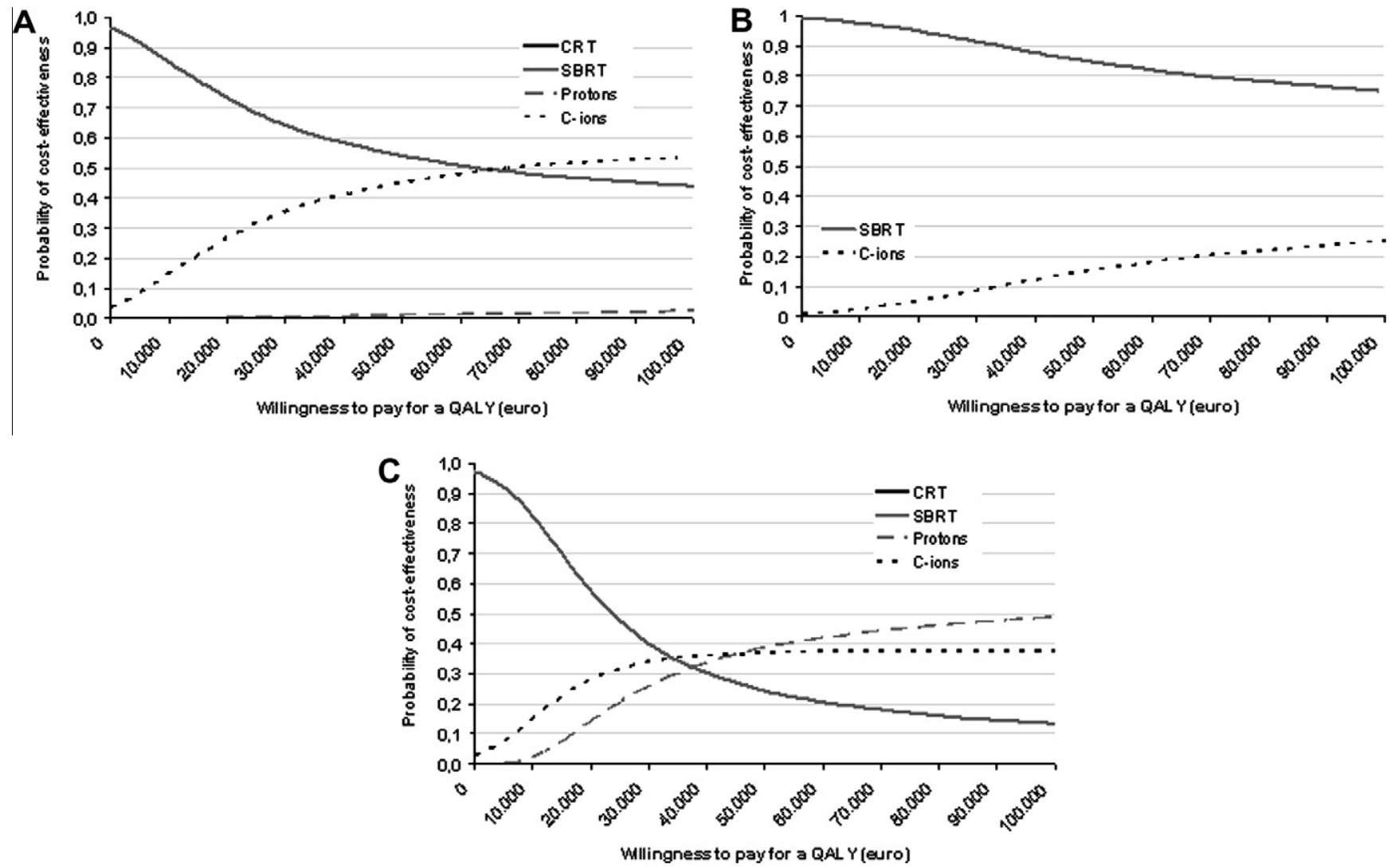

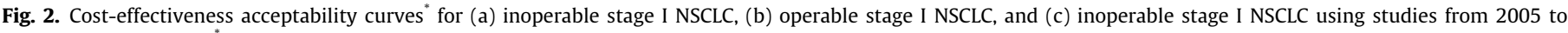

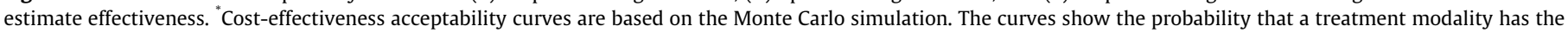
highest net monetary benefit, and thus is deemed cost-effective, given different amounts of how much society is willing to pay for a unit of effect (ceiling ratio).

The parameter group most valuable for further research was the effectiveness of carbon-ion therapy (Fig. 4). Other valuable topics for further research were the effectiveness of SBRT and the treatment costs. Regarding treatment costs, it was most valuable to acquire more evidence on the number of fractions per treatment.

\section{Discussion}

To the best of our knowledge, this is the first study to examine the cost-effectiveness of particle therapy in lung cancer. We reviewed and synthesized all available evidence to inform decision-making on this topic. We were not able to calculate the cost-effectiveness of particle therapy for lung cancer as a whole, due to a lack of evidence and variation in comparative treatment options between different stages of lung cancer. Consequently, we focused on exploring the cost-effectiveness of particle therapy for stage I NSCLC, as this subgroup of patients had been the focus of almost all particle research in lung cancer to date. Although considerable uncertainty exists, the results presented in this paper are valuable for decision-making in terms of policy and future research.

For inoperable stage I NSCLC carbon-ion therapy was found to cost $€ 67.257$ per QALY gained compared to SBRT. Both treatments dominated proton therapy and CRT. Assuming a ceiling ratio of $€ 80.000$, carbon-ion therapy may be cost-effective in inoperable stage I NSCLC. However, the probability of carbon-ion therapy being cost-effective was only $52 \%$. This indicates that, when carbon-ion therapy is implemented because of its acceptable costeffectiveness in this patient group, there is a $48 \%$ probability that this would be a wrong decision. Moreover, when using only recent studies to estimate the effectiveness, proton therapy had the highest probability of being cost-effective (46\%). These results emphasize the uncertainty surrounding the cost-effectiveness of particle therapy in inoperable stage I NSCLC, and the influence of which studies are included in the analyses. The uncertainty is also reflected in the high value of perfect information. This value should be considered an upper bound, because some uncertainty will always exist. The population EVPI can however be considered a conservative estimate, because future research may not only be valuable for Dutch NSCLC patients, but also for patients from other countries. Despite the uncertainty we can conclude with certainty that conventional radiotherapy with photons is not cost-effective in inoperable stage I NSCLC. For operable stage I NSCLC SBRT was found to dominate carbon-ion therapy.

Because we have synthesized evidence from various sources and various settings, we believe that the results of the present study are to a large extent generalizable to other settings and countries. However, because of the use of Dutch unit costs we conservatively decided to calculate the population EVPI only for the Dutch population. The assumption that the current decision problem is relevant for all stage I inoperable NSCLC patients worldwide would result in a population EVPI of $€ 2.836$ million. ${ }^{2}$ Given the detailed presentation of the model and its input parameters, those interested can assess the transferability of the results to their specific situation. ${ }^{38}$

The main limitation of the present study is the fact that only limited data, derived from published single-arm studies, are available on the effectiveness of particle therapy. Because of a lack of data we were not able to distinguish patients with a recurrence, both in costs and health state utility, and for the estimates of a number of cost parameters we had to rely on expert opinion. These 


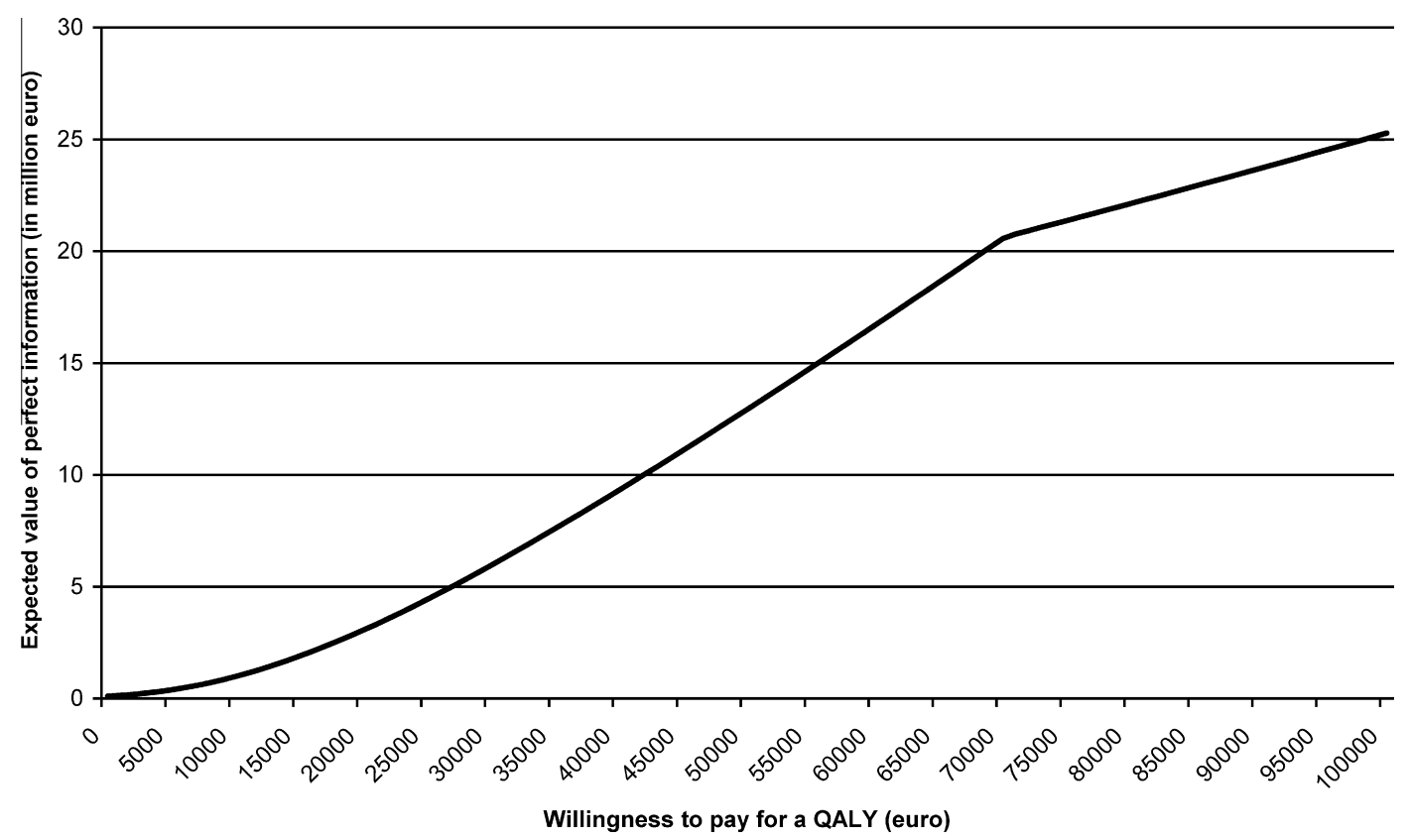

Fig. 3. Population expected value of perfect information curve for inoperable stage I NSCLC.

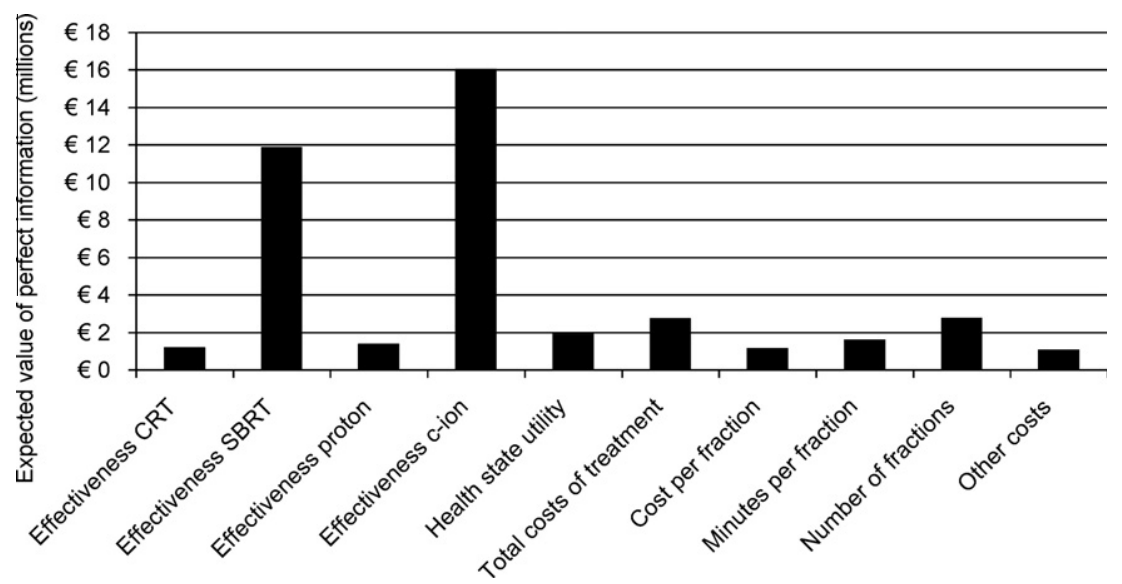

Fig. 4. Expected value of perfect information for parameter groups for inoperable stage I NSCLC.

shortcomings are not specific for particle therapy. An acknowledged challenge of early assessment of new technologies is to deal with lack of evidence. ${ }^{39}$ Moreover, modeling always involves simplification, and a model should not be faulted because available data do not meet the ideal standards of scientific evidence. ${ }^{7}$ That is, decisions are being made worldwide at the moment, so it is better to inform these decisions with the available evidence under conditions of uncertainty, than without any evidence at all. Although the present study shows the potential cost-effectiveness of particle therapy in NSCLC, it emphasizes the uncertainty surrounding this cost-effectiveness and the high probility of making a wrong decision, whatever decision is made. It is important that, when new evidence becomes available, reassessment of the costeffectiveness of particle therapy in lung cancer should be carried out.

Another challenge of this early assessment is that particle therapy is an evolving technology. It is possible that the effectiveness will improve, that the number of fractions will change and that the costs will either raise or reduce. We have anticipated on these changes in the probabilistic sensitivity analysis, by assigning accurate distributions to the parameters in the model. However, this again emphasizes the need to reassess the cost-effectiveness when new evidence becomes available.

Further research is needed to reduce the existing uncertainty. The present analysis showed that for inoperable stage I NSCLC further research was most valuable for the effectiveness of carbon-ion therapy and SBRT. However, the improved results for proton therapy when only recent studies were used indicate that proton therapy is still improving and further research may also be valuable for proton therapy. As SBRT is especially suitable for small tumors, it may be interesting to examine particle therapy in larger stage I/II tumors. Not enough evidence is currently available to quantify the effectiveness for these subgroups. Despite the limited evidence, the results of the present study suggest that it is unlikely that particle therapy will be cost-effective compared to SBRT in operable stage I NSCLC. Although beyond the scope of this paper, it would be interesting to examine the cost-effectiveness of SBRT compared to surgery in these patients. Randomized trials on this comparison are currently ongoing. Although beyond the scope of the present paper, value of information analysis is also useful in designing 
future trials. It can assist in choosing relevant outcome parameters as was demonstrated in the current study, but also for example in calculating the optimal sample size. ${ }^{40}$

Due to a lack of data no analysis could be performed for more advanced stage NSCLC. Preliminary data on concurrent chemotherapy with protons, showing reduced adverse events despite a higher radiation dose to the tumor, are promising. ${ }^{41-43}$ It would be interesting to examine the cost-effectiveness in this patient group when more mature data become available.

The current paper demonstrates the use and usefulness of decision-analytic modeling in areas where both effectiveness and costs are uncertain. By presenting the results under uncertainty, the current paper informs policy and research decisions. Value of information analysis is a relatively new and gradually increasing technique in health care, and to date a limited number of studies have applied the technique in the field of oncology. ${ }^{44-47}$ Given the present results, adoption of particle therapy as standard treatment in NSCLC is not recommended at this stage. Besides the relatively high probability of particle therapy not being costeffective, an important reason for this is the high investment risk associated with particle therapy. However, postponing the decision to adopt a potentially cost-effective treatment induces costs in terms of health benefits forgone. Because of the high value of information, it is recommended to acquire more evidence on the effectiveness of particle therapy in NSCLC. However, collecting clinical evidence requires particle facilities. Therefore, it might be worthwhile to invest in a particle facility, which should initially be used for clinical research only. Building on the analyses in the present study, a next step would be to make a trade-off between the investment risk, value of information and option value of delay. ${ }^{48}$

\section{Conflict of interest statement}

No actual or potential conflicts of interest exist.

\section{Acknowledgement}

This study was funded by an unrestricted grant from Siemens Medical Solutions.

We thank Tadaaki Miyamoto from the National Institute of Radiological Science in Chiba for providing us with data on operable stage I NSCLC patients. We thank Martijn Engelsman from the F.H. Burr Proton Therapy Center in Boston for his expertise. Hans Langendijk and Erwin Wiegman from the University Medical Centre Groningen, Miranda Dirx and Anita Botterweck from the Maastricht Cancer registry, Monique Hochstenbag from the Maastricht University Medical Centre and Ellen Dekkers from Maastro Clinic are acknowledged for their contribution to the utility study. Any remaining errors are the responsibility of the authors alone.

\section{References}

1. Jemal A, Siegel R, Ward E, Hao Y, Xu J, Thun MJ. Cancer statistics, 2009. CA Cancer J Clin 2009;59:225-49.

2. Youlden DR, Cramb SM, Baade PD. The International Epidemiology of Lung Cancer: geographical distribution and secular trends. I Thorac Oncol 2008;3:819-31.

3. Meropol NJ, Schrag D, Smith TJ, et al. American Society of Clinical Oncology guidance statement: the cost of cancer care. J Clin Oncol 2009;27:3868-74.

4. Drummond MF, Sculpher MJ, Torrance GW, O'Brien BJ, Stoddart GL. Methods for the economic evaluation of health care programmes. 3rd ed. Oxford: Oxford University Press; 2005.

5. Grutters JPC, Kessels AGH, Pijls-Johannesma M, De Ruysscher D, Joore MA Lambin P. Comparison of the effectiveness of radiotherapy with photons, protons and carbon-ions for stage I to III non-small cell lung cancer: a metaanalysis. Radiother Oncol, in press. doi:10.1016/j.radonc.2009.08.003.
6. Pijls-Johannesma M, Grutters JP, Lambin P, Ruysscher DD. Particle therapy in lung cancer: where do we stand? Cancer Treat Rev.

7. Weinstein MC, O’Brien B, Hornberger J, et al. Principles of good practice for decision analytic modeling in health-care evaluation: report of the ISPOR Task Force on Good Research Practices - Modeling Studies. Value Health 2003;6:9-17.

8. Briggs A, Sculpher M, Claxton K. Decision modelling for health economic evaluation. Oxford: Oxford University Press; 2006.

9. Claxton K, Sculpher M, Drummond M. A rational framework for decision making by the National Institute for Clinical Excellence (NICE). Lancet 2002;360:711-5.

10. Glatstein E, Glick J, Kaiser L, Hahn SM. Should randomized clinical trials be required for proton radiotherapy? An alternative view. J Clin Oncol 2008;26:2438-9.

11. Goitein M, Cox JD. Should randomized clinical trials be required for proton radiotherapy? J Clin Oncol 2008;26:175-6.

12. Anonymous. Introducing new treatments, technologies into the clinic. J Clin Oncol 2008;26:2425.

13. Glimelius B, Montelius A. Proton beam therapy - do we need the randomised trials and can we do them? Radiother Oncol 2007;83:105-9.

14. Goitein M. Magical protons? Int J Radiat Oncol Biol Phys 2008;70:654-6.

15. Lewis BE. On equipoise and emerging technologies. J Clin Oncol 2008;26:2590.

16. Macbeth FR, Williams MV. Proton therapy should be tested in randomized trials. J Clin Oncol 2008;26:2590-a-1.

17. Morgan JP. A patient's perspective on randomized clinical trials for proton radiotherapy. J Clin Oncol 2008;26:2592.

18. Suit H, Kooy H, Trofimov A, et al. Should positive phase III clinical trial data be required before proton beam therapy is more widely adopted? No Radiother Oncol 2008;86:148-53.

19. Tepper JE. Protons and parachutes. J Clin Oncol 2008;26:2436-7.

20. Common Terminology Criteria for Adverse Events, version 3.0 (CTCAE). <http:// ctep.cancer.gov/protocolDevelopment/electronic_applications/docs/ ctcaev3.pdf $>; 2006$ accessed 03.02.2010.

21. Hall EJ. Intensity-modulated radiation therapy, protons, and the risk of second cancers. Int J Radiat Oncol Biol Phys 2006;65:1-7.

22. Paganetti H. The impact of protons on the incidence of second malignancies in radiotherapy by Eric J. Hall (Supp.31-34; 2007). Technol Cancer Res Treat, 2007;6:661-662.

23. Paganetti $\mathrm{H}$, Bortfeld $\mathrm{T}$, Delaney TF. Neutron dose in proton radiation therapy: in regard to Eric J. Hall (Int J Radiat Oncol Biol Phys, 2006;65:1-7). Int J Radiat Oncol Biol Phys, 2006;66:1594-1595 author reply 5.

24. Onishi $H$, Shirato $H$, Nagata $Y$, et al. Hypofractionated stereotactic radiotherapy (HypoFXSRT) for stage I non-small cell lung cancer: updated results of 257 patients in a Japanese multi-institutional study. $J$ Thorac Oncol 2007;2:S94-S100.

25. Uematsu M, Shioda A, Suda A, et al. Computed tomography-guided frameless stereotactic radiotherapy for stage I non-small cell lung cancer: a 5-year experience. Int J Radiat Oncol Biol Phys 2001;51:666-70.

26. Miyamoto T, Baba M, Sugane T, et al. Carbon ion radiotherapy for stage I nonsmall cell lung cancer using a regimen of four fractions during 1 week. J Thorac Oncol 2007;2:916-26.

27. Miyamoto T, Baba M, Yamamoto N, et al. Curative treatment of stage I nonsmall-cell lung cancer with carbon ion beams using a hypofractionated regimen. Int J Radiat Oncol Biol Phys 2007;67:750-8.

28. The EuroQol Group. EuroQol - a new facility for the measurement of healthrelated quality of life. Health Policy 1990;16:199-208.

29. Dolan P. Modeling valuations for EuroQol health states. Med Care 1997; 35:1095-108

30. Health Care Insurance Board. Guidelines for pharmaco-economic research (in Dutch). Diemen: Health Care Insurance Board; 2006.

31. Oostenbrink JB, Koopmanschap MA, Rutten FFH. Manual for costing research (in Dutch). Amstelveen: College voor zorgverzekeringen; 2004.

32. Peeters A, Grutters JPC, Pijls-Johannesma M, et al. How costly is radiotherapy with particles? Cost analysis of external beam radiotherapy with carbon ions, protons and photons. Radiother Oncol, in press. doi:10.1016/j.radonc. 2009.12.002.

33. Council for Public Health and Health Care. Sensible and sustainable care (in Dutch). Zoetermeer: Council for Public Health and Health Care; 2006.

34. van Hout BA, Al MJ, Gordon GS, Rutten FF. Costs, effects and C/E-ratios alongside a clinical trial. Health Econ 1994;3:309-19.

35. Hoyer M. Improved accuracy and outcome in radiotherapy of lung cancer. Radiother Oncol 2008;87:1-2.

36. Claxton K, Posnett J. An economic approach to clinical trial design and research priority-setting. Health Econ 1996;5:513-24.

37. Dutch Cancer Registry. <http://www.ikcnet.nl/index.php>; 2010 accessed 12.02 .2010

38. Welte R, Feenstra T, Jager H, Leidl R. A decision chart for assessing and improving the transferability of economic evaluation results between countries. Pharmacoeconomics 2004;22:857-76.

39. Wild C, Langer T. Emerging health technologies: informing and supporting health policy early. Health Policy 2008;87:160-71.

40. Willan A, Kowgier M. Determining optimal sample sizes for multi-stage randomized clinical trials using value of information methods. Clin Trials 2008;5:289-300.

41. Cox JD, Chang J, Liao Z, et al. Acute esophageal reactions from proton beam therapy, concurrent chemotherapy for non-small cell lung cancer (NSCLC): reduction in incidence, severity despite higher doses. JThorac Oncol 2007;2:S449. 
42. Komaki R, Sejpal SV, Wei X, et al. Reduction of bone marrow suppression for patients with stage III NSCLC treated by proton and chemotherapy compared with IMRT and chemotherapy. In: Conference of the particle therapy co-operative group, vol. 47. Jacksonville, Florida; 2008. p. 14.

43. Sejpal SV, Komaki $R$, Wei X, et al. Does proton beam radiotherapy (PBT) reduce treatment related pneumonitis (TRP) compared to intensity modulated related radiation therapy (IMRT) in patients with locally advanced non-small cell lung cancer (NSCLC) treated with concurrent chemotherapy? In: Conference of the particle therapy co-operative group, vol. 47. Jacksonville, Florida; 2008. p. 22.

44. Collins R, Fenwick E, Trowman R, et al. A systematic review and economic model of the clinical effectiveness and cost-effectiveness of docetaxel in combination with prednisone or prednisolone for the treatment of hormonerefractory metastatic prostate cancer. Health Technol Assess 2007;11.. p. iii-iv, xv-xviii, 1-179.
45. Garside R, Pitt M, Somerville M, Stein K, Price A, Gilbert N. Surveillance of Barrett's oesophagus: exploring the uncertainty through systematic review, expert workshop and economic modelling. Health Technol Assess 2006;10.. p. 1 142, iii-iv.

46. Hassan C, Pickhardt PJ, Di Giulio E, Hunink MG, Zullo A, Nardelli BB. Value-ofinformation analysis to guide future research in the management of the colorectal malignant polyp. Dis Colon Rectum 2010;53:135-42.

47. Carlson JJ, Garrison LP, Ramsey SD, Veenstra DL. The potential clinical and economic outcomes of pharmacogenomic approaches to EGFR-tyrosine kinase inhibitor therapy in non-small-cell lung cancer. Value Health 2009;12:20-7.

48. Eckermann S, Willan AR. Expected value of information and decision making in HTA. Health Econ 2007;16:195-209. 